\title{
Research Paper: The Effects of Ripe Pistachio Hulls Hydro- alcoholic Extract and Aerobic Training on Learning and Memory in Streptozotocin-induced Diabetic Male Rats
}

\author{
Sajad Abdi Gorabi ${ }^{1}$ (D), Hasan Mohammadzadeh ${ }^{1}$ (D), Mohammad Rostampour ${ }^{2,3^{*}}$ (D) \\ 1. Department of Motor Behavior, Faculty of Physical Education and Sport Sciences, University of Urmia, Urmia, Iran. \\ 2. Cellular and Molecular Research Center, School of Medicine, Guilan University of Medical Sciences, Rasht, Iran. \\ 3. Department of Physiology, School of Medicine, Guilan University of Medical Sciences, Rasht, Iran.
}

\begin{tabular}{|l|l|l|l|l}
\hline $\begin{array}{l}\text { Use your device to scan } \\
\text { and read the article online }\end{array}$ & $\begin{array}{l}\text { Extract and Aerobic Training on Learning and Memory in Streptozotocin-induced Diabetic Male Rats. Basic and Clinical Neuro- } \\
\text { science, 11(4), 525-534. http://dx.doi.org/10.32598/bcn.9.10.400 }\end{array}$ \\
\hline
\end{tabular}

\section{(i) (3)}

Article info:

Received: 26 Nov 2018

First Revision: 10 Dec 2018

Accepted: 19 Jan 2019

Available Online: 01 Jul 2020

Keywords:

Ripe pistachio Hulls, Aerobic Training, Learning and memory, Streptozotocin-diabetic rats

\begin{abstract}
A B S T RA C T
Introduction: Diabetes mellitus has harmful effects on body functions, such as learning and memory. According to the role of exercise and medicinal plants on body health, the purpose of this study was to survey the effect of combined aerobic training and the use of Ripe Pistachio Hulls (RPH) hydro-alcoholic extract on learning and memory in streptozotocin-induced diabetic male rats.

Methods: In this experimental study, 42 male Wistar rats weighing 250-280 g were used in 6 groups with an equal number of 7 rats in each one. Streptozotocin (STZ) $(50 \mathrm{mg} / \mathrm{kg})$ was used to induce diabetes , and the test protocol was applied for 8 weeks. Passive avoidance memory was assessed using a step-through passive avoidance apparatus (shuttle box). SPSS software was used to analyze the data and $\mathrm{P}<0.05$ was significant.

Results: The results showed that step-through latency in the acquisition trial (STLa) was not significantly different among groups. Step-through latency in retrieval (STLr 24) test significantly reduced and time spent in The Dark Compartment (TDC) decreased in treated groups compared with the diabetic control groups $(\mathrm{P}<0.001)$. Also, there was no significant difference between the STZ and saline diabetic groups.

Conclusion: The findings of this study revealed that the RPH hydro-alcoholic extract and aerobic exercise could improve passive avoidance memory in streptozotocin diabetic rats Meanwhile, they might be an adjuvant therapy combined with other traditional medicine.
\end{abstract}




\section{Highlights}

- Diabetes mellitus is an endocrine disorders.

- Diabetes mellitus impaired passive avoidance memory of rats.

- Aerobic Training and Ripe Pistachio hulls hydroalcoholic extract alone or simultaneously ameliorated memory impairment due to diabetes mellitus.

\section{Plain Language Summary}

Diabetes mellitus is a serious disorder that more than 347 million people suffered from it worldwide until 2011. WHO has predicted it will increase to 366 million of people with diabetes mellitus in 2025. It has harmful effects on body function such as learning and memory. In this research we investigated the effect of ripe pistachio hulls extract and aerobic training on impaired learning and memory of diabetes mellitus rats. The ripe pistachio extract could ameliorate the memory impairment caused by diabetes mellitus. The conclusion of our study showed that a proper life style can protect our health.

\section{Introduction}

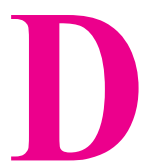

iabetes mellitus is one of the most serious endocrine disorders. It is estimated that over 347 million people worldwide have suffered from this disease until 2011 (Danaei et al., 2011). The World Health Organization (WHO) has predicted that the number of people with diabetes will increase to 366 million in 2025 (Young et al., 1992). Also, the WHO reported that nearly 35.6 million people live with dementia. It is expected that this number might be doubled by 2030 (65.7 million), and it can reach more than triple rate by 2050 (115.4 million) (Ammari et al., 2018). The new lifestyle of urban living, lack of exercise, and unhealthy nutrition, along with the consumption of fatty and sweet foods, are among the factors that cause health damage, the development of metabolic diseases, and the loss of human life. One of the metabolic diseases is diabetes. It is an autoimmune disease, in which genetic factors, environmental stress, viral infections, and diet can bring about the destruction of the insulin-producing beta cells in the pancreas. Disruption of cognitive and nonnormalization of neurochemical compounds and brain structures in diabetic patients and rodent diabetic rats with streptozotocin (STZ) has been reported (Young et al., 1992; Ogonovszky et al., 2005). Furthermore, memory and learning, ability to solve problems, speed of exercise, mental and complex physical movements, inference, and understanding of the diabetic patients are damaged (Ramanathan \& Jaiswal, 1998).
Many studies have been conducted on the treatment of diabetes using medicinal herbs. The protective effects of plant extracts, including cumin, fenugreek, sage, moss, etc. have been confirmed in diabetic rats (Shahbazi \& Maleknia, 2008). Pistachio is one of the most widely used herbs in traditional medicine. Hull is the largest byproduct of pistachio (accounting for on average between $35 \%$ and $45 \%$ ) during industrial post-harvest processing (Grace et al., 2016; Barreca et al., 2016). It was reported that ethanol extract of ripe pistachio hulls $(\mathrm{RPH})$ contains a large diversity of phenolic acid, flavonoids, flavonols, flavones, and flavonols (Barreca et al., 2016). Based on its constituents, RPH could be a cost-effective source of compounds with health-protective potential. Also, RPH phenolic derivative might be used as a natural alternative to synthetic antioxidants (Grace et al., 2016; Sevcan, Ozlem, Reinhold, \& Ralf, 2017). The role of flavonoids in memory enhancement has been shown (Nishimura, Taki \& Takaishi, 2000).

Aerobic exercises could improve memory and learning (Khalaj \& Ahmadi, 2016). Also, physical activity has a critical role in blood glucose management and overall health in individuals with diabetes and pre-diabetes (Colberg et al., 2016). Over several decades, an exercise in human and animal models could help to maintain brain functions, such as cognitive performance, and it can even protect the central nervous system and improve learning/memory functions following chronic exercise (Yi, 2015). Because exercise and some medicinal plants can have beneficial effects on memory in diabetic rats, the present study was designed to investigate the effect 
of RPH hydro-alcoholic extract and aerobic exercise on learning and memory of STZ-diabetic male rats.

\section{Materials and Methods}

2.1. Chemicals and preparation of RPH hydro-alcoholic extract

STZ was purchased from Sigma-Aldrich (St. Louis, MO, USA) and dissolved in saline. The ripe pistachio (Pistacia vera, L.) nuts of Ohadi cultivar were obtained from 13-year-old trees grown in the Damghan region of Semnan Province, Iran in 2013. The plants were authenticated by the associate professor Davood Bakhshi, a pomologist in the Faculty of Agriculture, University of Guilan, Rasht, Iran. The fleshy fruit wall of the fresh and ripe pistachios was removed and dried in an oven at $40^{\circ} \mathrm{C}$. Fifty grams of the fine powder of RPH was mixed with $70 \%$ ethanol $(70 \%$ ethanol and $30 \%$ distilled water $)$ and placed on a shaker incubator with gentle shaking for $72 \mathrm{~h}$. Afterward, the liquid phase of the container was placed on the funnel and then dried. The dried extract was weighed and resuspended in normal saline. Animals received an appropriate amount of extract according to their weight and protocol. Meanwhile, the administration of the extract in saline solution was carried out by the gavage method $(10 \mathrm{ml} / \mathrm{kg})$.

Various doses of RPH hydro-alcoholic extract $(1,5,10$, 50,100 , and $500 \mathrm{mg} / \mathrm{kg}$ ) were administered to rats by gavage for 2 months before training, and only the extract at a dose of $10 \mathrm{mg} / \mathrm{kg}$ significantly increased the STLr $24 \mathrm{~h}$ compared with the saline group $(\mathrm{P}<0.05)$ and there was a significant reduction in the TDC than the sham and saline groups $(\mathrm{P}<0.01$ and $\mathrm{P}<0.05$, respectively). Therefore, the dose of $10 \mathrm{mg} / \mathrm{kg}$ of the RPH extract was selected as an effective dose.

\subsection{Animals}

In this experimental study, 42 male Wistar rats weighing 250-280 g were used ( $\mathrm{n}=7$ in each group) and kept at the Animal House of Guilan University of Medical Sciences at a temperature of $20 \pm 2^{\circ} \mathrm{C}$ and a light-dark cycle of $12 \mathrm{~h}$ (the start of lighting at 9 am and the start of darkness at $9 \mathrm{pm}$ ) four rats per cage with standard water and food available. All behavioral tests were conducted from 10:00 am to 4:00 pm. All animal experiments were carried out in accordance with the National Institute of Health Guide for the Care and Use of Laboratory Animals (Publication No.: 85-23 revised in 1985). All protocols were also approved by ethical and supervisory guidelines of working with experimental animals of Guilan University of Medical Sciences (Code No.: IR.GUMS.REC.1395.27). The cages were cleaned twice a day, and during this time, animals were checked for their sugars, and if they reached the fetal border, they were injected with insulin. Rats were randomly divided into six groups of seven rats: (1) the sham group, which included non-diabetic rats and did not get any medicine or exercise (2) STZ group, which included diabetic rats that they did not get any medicine or exercise); (3) the diabetic group that received normal saline as the solvent of RPH (STZ+Saline); (4) the diabetic group that received RPH hydro-alcoholic extract (STZ+RPH); (5) the diabetic group that was subjected to running on the treadmill for 8 weeks and training for $24 \mathrm{~h}$ (STZ+exercise); and (6) the diabetic group that received RPH hydro-alcoholic extract plus aerobic exercises.

\subsection{Induction of diabetes}

After controlling and recording the weight, the intravenous blood glucose of all animals was measured by using the Accu Check glucose meter, and the fasting blood glucose level was less than $200 \mathrm{mg} / \mathrm{dl}$ without fasting. Then, after $24 \mathrm{~h}$ of fasting, diabetes was induced by an intraperitoneal injection of STZ at a dose of $50 \mathrm{mg}$ /kg (Firouzjaei, Jafari, Eskandari, Anarkoli, \& Alipour, 2013). For injection, STZ was dissolved in cold saline $(1 \mathrm{ml} / \mathrm{kg}$ ) solution, injected at 8:00 am, and in fasting state to the rats. Three days (72 h) after STZ injection, blood glucose was monitored in animals. The criterion for diabetic rats was considered as a blood glucose level of above $250 \mathrm{mg} / \mathrm{dl}$; therefore, other animals were excluded from the study (Firouzjaei, et al., 2013; Hasanein \& Shahidi, 2012; Jabbarpour et al., 2014).

\subsection{Aerobic exercises}

At first, rats passed the adaptation period by rat treadmill. During this period, recurring short-term training courses were used during four consecutive days (each training session included a 5-minute course of $10 \mathrm{~m} / \mathrm{min}$ daily). The untrained animals were eliminated after the adaptation period. One day of resting was considered, and then the main phase of training began. In the first week, animals ran a treadmill with a gradient of zero and a speed of $10 \mathrm{~m} / \mathrm{min}$ for $10 \mathrm{~min}$. In the second week, after $5 \mathrm{~min}$ running at a speed of $10 \mathrm{~m} / \mathrm{min}$, the speed reached $20 \mathrm{~m} / \mathrm{min}$ with the same zero gradient and running for $10 \mathrm{~min}$. This period of the practice continued for 8 weeks (Verma \& Bordia, 1998). After a period of practice, animals of different groups were tested using standard devices for learning and memory. 


\subsection{Passive avoidance learning and memory}

After eight weeks of practice, the passive avoidance learning and memory of different diabetic groups of animals were evaluated using the Shuttle Box apparatus purchased from Borj Sanat Co. Long-term memory evaluation was based on negative reinforcement. This instrument had two compartments, the mechanical part, and the controller or the electronic part. Two chambers were separated by an $8 \times 8 \mathrm{~cm}$ guillotine door. The dimensions of each chamber were $20 \times 21 \times 20 \mathrm{~cm}$. On the floor of each of these two chambers, the bars $(2.5 \mathrm{~mm}$ in diameter) are spaced $1 \mathrm{~cm}$ apart, which acts as a network for transporting electric shock to an animal. The control part determines the duration, frequency, and shock intensity. The habituation stage consists of two steps that take place at intervals of $30 \mathrm{~min}$. At this stage, the rat was placed in a white chamber and the guillotine door was opened in $10 \mathrm{~s}$ and step-through latency was recorded until the animal entered the dark chamber. When the animal entered the dark chamber, the guillotine door was closed and the animal was taken out of the dark chamber, and after each stage, the animal was placed in its individual cage. The training took place $30 \mathrm{~min}$ after the second habituation stage. Thus, the rat was placed in the white chamber, and after $10 \mathrm{~s}$, the guillotine door was raised. The Step-Through Latency (STL) of the animal was recorded and the electric current was fed to the animal's paws for 1 sat a frequency of $50 \mathrm{~Hz}$ for $2 \mathrm{~s}$ and it was repeated $120 \mathrm{~s}$ later. When the rat did not enter the dark chamber, the test was stopped; however, the shock was delivered when the animal entered the dark chamber. After three tests, if the rat was not able to complete the task, it was removed from the test. This step was performed $24 \mathrm{~h}$ after training to assess long-term memory. The test lasted for $10 \mathrm{~min}$. Two timers were used to record the desired time for the test. At first, the rat was placed in a white chamber and the guillotine door was opened after $10 \mathrm{~s}$, and step-through latency of animal into the dark chamber was recorded. Finally, the total time spent in the dark chamber (TDC) was recorded for $10 \mathrm{~min}$ (Firouzjaei, et al., 2013).

\subsection{Statistical analysis}

Data were analyzed using SPSS software. Data are shown as Mean \pm SEM. The Kolmogorov-Smirnov test was used to ensure the normal distribution of data. If the distribution was normal, the results were compared using the one-way analysis of variance (ANOVA), followed by the Tuckey's post-hoc test; otherwise, the KruskalWallis statistical test was used. $\mathrm{P}<0.05$ was considered as a significant level.

\section{Results}

3.1. The amount of step-through latency in acquisition trial (STLa)

The results showed that the STLa increased in the sham, STZ+RPH, STZ+exercise, and STZ+RPH+exercise groups in comparison with the STZ and STZ+saline groups, but these changes were not significant (Figure 1).

\subsection{Step-through latency in the retrieval (STLr)}

The 24-hour post-training memory test showed a significant difference between the groups in $\operatorname{STLr}(\mathrm{P}<0.001)$. The intra-group comparison showed no significant difference between STZ and saline diabetic groups. On

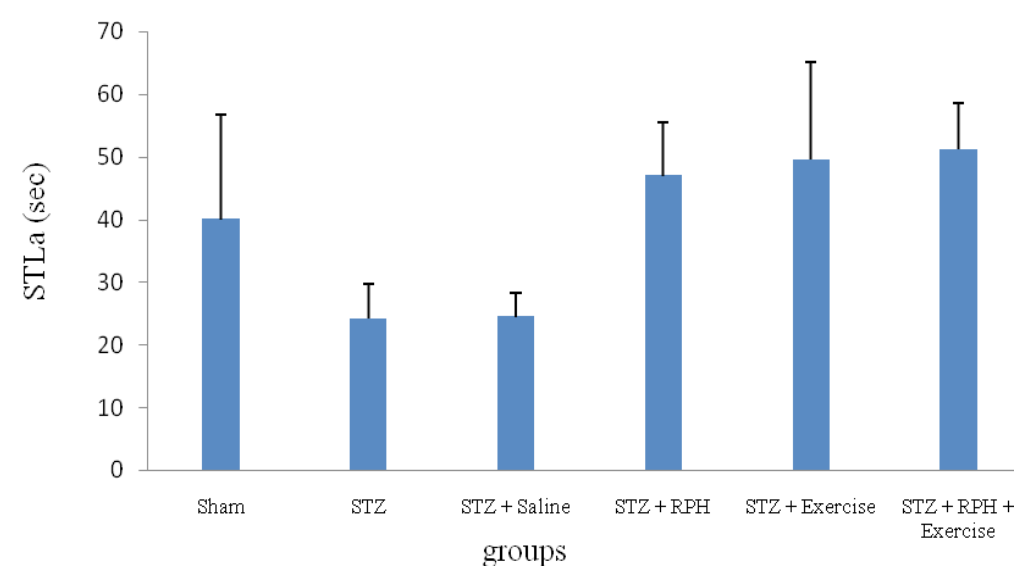

Figure 1. Comparison of step-through latency in the acquisition trial (STLa)

In the sham, STZ, STZ+saline, STZ+RPH, STZ+exercise, and STZ+RPH+exercise groups in passive avoidance learning test (Mean \pm SEM, $\mathrm{n}=7$ ). 


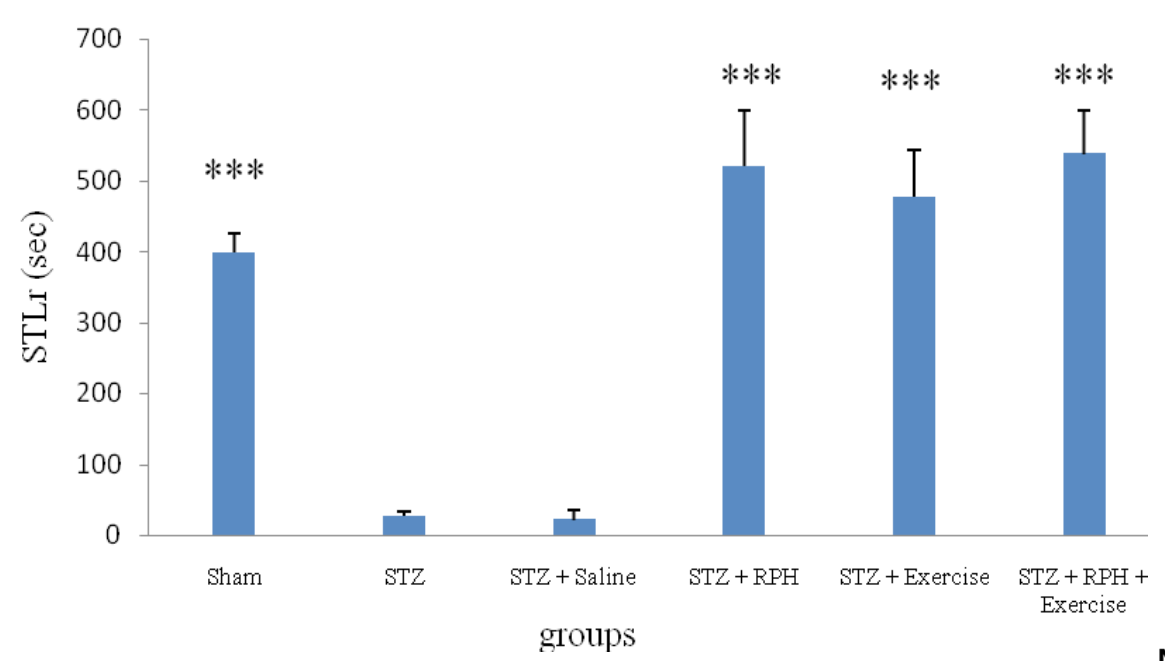

Figure 2. Comparison of step-through latencyin the retrieval (STLr)

In the sham, STZ, STZ+saline, STZ+RPH, STZ+exercise, and STZ+RPH+exercise groups in passive avoidance learning test; *** $\mathrm{P}<0.001$ compared with the $\mathrm{STZ}$ and $\mathrm{STZ}+$ saline diabetic groups (Mean $\pm S E M, n=7$ ).

the other hand, there were significant differences in the STZ and saline diabetic groups compared with the sham, STZ+RPH, STZ+ exercise, and STZ+ RPH+exercise groups $(\mathrm{P}<0.001)$ (Figure 2$)$.

\subsection{TDC}

Intra-group comparisons showed no significant difference between the STZ and saline diabetic groups. On the other hand, there were significant differences in the STZ and saline diabetic groups compared with the sham, STZ+RPH, STZ+exercise, and STZ+RPH+exercise groups $(\mathrm{P}<0.001)$ (Figure 3$)$.

\section{Discussion}

In the present study, the effect of RPH hydro-alcoholic extract and aerobic training on learning and memory in STZ-induced diabetic male rats was studied. The results of this study showed that aerobic exercise and RPH hydro-alcoholic extract alone or in combination improved learning and memory deficits in diabetic rats and the memory improvement in treated groups was significant compared with the diabetic control groups.

STZ-induced diabetes reduces memory performance (Flores-Gómez, de Jesús Gomez-Villalobos, \& Flores, 2018). In previous studies, learning and memory deficits have been reported in both diabetic humans and animals (Patil, Singh, \& Kulkarni, 2006; Kucukatay,

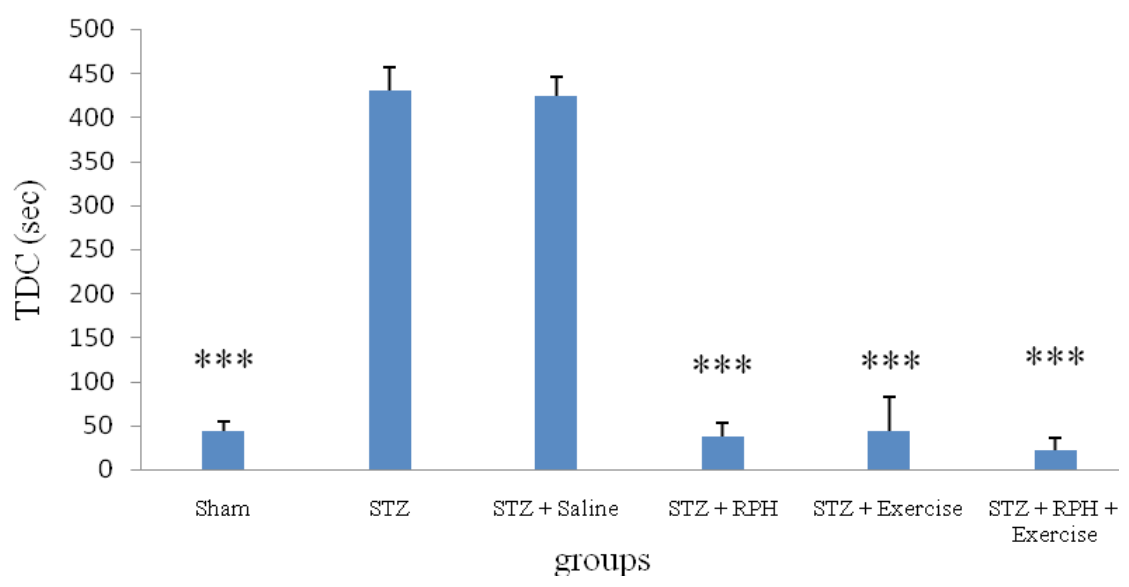

Figure 3. Comparison of the time spent in the dark compartment (TDC)

In the sham, STZ, STZ+saline, STZ+RPH, STZ+exercise, and STZ+RPH+exercise groups in passive avoidance learning test *** $\mathrm{P}<0.001$ compared with the STZ and STZ+saline diabetic groups (Mean $\pm \mathrm{SEM}, \mathrm{n}=7$ ). 
Agar, Gumuslu, \& Yargicoglu, 2007). In the memory test, in diabetic rats, the latency to enter the dark chamber (STLr) decreased and TDC increased, indicating memory impairment following diabetes mellitus. The increase in STLr cannot be attributed to the sensory or motor impairment of the animals. Because the value of STLa before the electric shock did not show a significant difference among the groups.

In the present study, the shuttle box apparatus was used to measure passive avoidance memory. Feeding the hydro-alcoholic extract of RPH at a dose of $10 \mathrm{mg}$ / $\mathrm{kg}$ caused a significant increase in STLr and a significant reduction in the TDC compared with the diabetic control groups. These results indicated that RPH extract improved memory impairment due to diabetes mellitus in rats. Phenolic compounds were found in the pistachio, with antioxidant, anti-inflammatory, and antimicrobial effects (Azadedel, Hanachi, \& Saboora, 2017). In epidemiological studies, it was proven that phenolic flavonoids, as antioxidants in pistachio red peal, have improved memory performance in older rats (Mozdastan, Ebrahimzadeh, \& Khalili, 2015).

Pistachio red skin has a parenchymal and fibrous structure. It also consists of minerals, such as potassium, magnesium, calcium, and sodium. Meanwhile, flavonoids are important compounds in this plant, which could increase cholinergic activity (Zhang, Tang, Zheng, Chen, \& Shen, 2011; Gao, Tang, He, \& Bi, 2012) and learning and memory (Thirugnanasambantham et al., 1990; Savelev, Okello, \& Perry, 2004). It was also proven that acetylcholine receptor stimulation increases memory and cognition (Baxter \& Crimins, 2018), and it seems that RPH extract increased memory through the potentiation of the cholinergic system.

The consumption of foods rich in polyphenols, including flavonoids, has a major impact on preserving brain function, improving learning and memory ability, and also contributes to the improvement of neuronal signaling in memory formation. Flavonoids have potent antioxidant and anti-inflammatory effects, which can slow down the process of reducing brain function due to aging. Flavonoids can improve blood flow to the brain and play an important role in increasing memory and learning ability. Possible mechanisms of the effects of flavonoids on brain function are effective processes for cell survival, differentiation, and memory formation. The mechanism of action of these compounds is different in the brain. Some act as estrogens and a group through neural signaling is involved in controlling morphological mechanisms that affect memory formation, resulting in enabling effective enzymes in these pathways to increase memory and learning ability (Van, Kempermann, \& Gage, 1999). Flavonoid-rich plants and foods could improve memory and synaptic plasticity. Flavonoids play an important role in improving human memory and neurocognitive performances by the protection of vulnerable neurons, as well as the elevation of existing neuronal function and regeneration (Spencer, 2008; Viggiano et al, 2006; Wang, Wang, Wu, \& Cai, 2006).

In this study, exercise could improve passive avoidance memory deficiency due to diabetes. Also, RPH consumption potentiated the incremental effect of exercise on memory. Various studies have confirmed the beneficial effects of physical activity and exercise on brain functions, such as memory enhancement (Grealy, Johnson, \& Rushton, 1999), cognitive function (Johansson \& Ohlsson, 1996), neurogenesis (Ohlsson \& Johansson, 1995), and improvement of brain injuries (Ogonovszky et al., 2005). Exercise, without adverse effects, prevents repression of cell proliferation due to STZ in the sinusoidal grooves of the brain, and somehow improves abnormalities and functions (Guo et al., 2008; Ding et al., 2005). Studies have shown that exercise improves brain resistance to injury and improves cognitive and motor processes (Radak et al., 2006; Spiegelman, 2013). Both structural and functional changes in the brain play an important role in improving memory and learning in response to exercise (Gordon, Benson, Bird, \& Fraser, 2009). Since exercise induces neurogenesis in humans, it decreases the risk of Alzheimer disease (Henriksen, 2002), Parkinson disease, and some other neurogenic disorders (Henriksen, 2002; Yuede et al., 2009). Exercise reduces blood glucose, and this decrease after exercise is associated with the increased response of the cells to insulin and improved insulin function (Gordon, Benson, Bird, \& Fraser, 2009). Previous studies have shown that exercise can increase the expression of glucose transporter (GLUT) proteins in skeletal muscle (Henriksen, 2002). Therefore, exercise via reducing blood glucose improves memory impairment by STZ. It has also been shown that exercise helps to change the antioxidant status of rats (Yuede et al., 2009).

Regular and continuous exercise has beneficial effects on the brain. Accordingly, exercise increases capillary growth, dendritic connections, and processing in the central nervous system (Cotman \& Berchtold, 2006). In addition, regular exercise reduces brain damage after stroke (Carro, Trejo, Busiguina, \& Torres- Aleman, 2001) as well as the severity of many age-related illnesses. It has been shown that aerobic exercise prevents a decrease in the amount of gray matter and mental ability in 
the age-old cortex (Colcombe, et al., 2004; Blomquist \& Danner, 1987; Evans et al., 1993). The long-term exercise results in an increase in the level of antioxidants and antioxidant enzymes that can protect the brain from oxidative damage; for example, after a long-term exercise, the levels of Malondialdehyde (MDA), a product of lipid peroxidation and oxidative stress biomarker, and ascorbic acid in the brain decreased and increased, respectively (Liu et al., 2000). Ascorbic acid, as a nerve modifier, improves memory and learning disorders caused by Alzheimer disease (Harrison, Hosseini, Dawes, Weaver, \& May, 2009).

Decreasing the BDNF mediates neurodegenerative disease such as Parkinson. Moderate to high intensity of training induces increase of BDNF receptors in the brain that prevents neurodegeneration (Małczyńska, Piotrowicz, Drabarek, Langfort, Małgorzata Chalimoniuk, 2019). Exercise through reducing the blood glucose helps to treat diabetes, and it is possible that by changes in the level of BDNF protein in the central and peripheral nerves in aerobic exercise regimens, it can reduce complications of diabetes. BDNF and its receptor, tyrosine kinase $\mathrm{B}$, are essential for learning and memory in the hippocampus. Among the neurotrophic factors, BDNF has the most significant role in learning and memory processes and synaptic flexibility. A long-term regular exercise is highly effective in reducing spatial memory loss caused by diabetes. Thus, it can be considered that the positive effect of exercise in modulating the complications of diabetes depends on its continuity and regularity (Mattson, Culmsee, Yu, \& Camandola, 2000; Monti, Polazzi, \& Contastabile, 2009).

\section{Conclusions}

According to our results, it can be concluded that the use of RPH hydro-alcoholic extract and aerobic training alone and simultaneously can improve passive avoidance memory in male diabetic rats. It might be considered as an adjuvant therapy with other traditional anti-diabetic medications. Nevertheless, further studies are necessary to indicate the probable mechanisms of their effects.

\section{Ethical Considerations}

\section{Compliance with ethical guidelines}

All protocols were approved by Ethical Committee of Guilan University of Medicale Sciences (code No. IR.GUMS.REC.1395.27).

\section{Funding}

This research was financially supported by the Guilan University of Medical Sciences, Rasht, Iran (Grant number: 95022104).

\section{Authors' contributions}

Investigation, and writing-original draft: Sajad Abdi, Mohammad Rostampour; Conceptualization, formal analysis: Sajad Abdi, Mohammad Rostampour; Data curation, meth-odology: All authors; Writing, reviewing, and editing: Sajad Abdi, Hasan Mohammadzadeh, Mohammad Rostampour ; Vi-sualization, supervision, project administration: Mohammad Rostampour.

\section{Conflict of interest}

The authors declared no conflict of interest.

\section{Acknowledgments}

We are grateful to Dr. Davod Bakhshi (associate professor of pomology), Agriculture Faculty of Guilan University, Rasht, Guilan, for plant authentication.

\section{References}

Ammari, M., Othman, H., Hajri, A., Sakly, M., \& Abdelmelek, H. (2018). Pistacia lentiscus oil attenuates memory dysfunction and decreases levels of biomarkers of oxidative stress induced by lipopolysaccharide in rats. Brain Research Bulletin, 140, 140-7. [DOI:10.1016/j.brainresbull.2018.04.014] [PMID]

Azadedel, S. H., Hanachi, P., \& Saboora, A. (2017). [Investigation on antioxidant activity of pistachio (Pistacia vera L.) skin extraction (Persian)]. Journal of Plant Research, 30(4), 827-835. http://plant. ijbio.ir/article_983_en.html

Barreca, D., Laganà, G., Leuzzi, U., Smeriglio, A., Trombetta, D., Bellocco, E. (2016). Evaluation of the nutraceutical, antioxidant and cytoprotective properties of ripe pistachio (Pistacia vera L., variety Bronte) hulls. Food Chemistry, (196), 493-502. [DOI:10.1016/j. foodchem.2015.09.077] [PMID]

Baxter, M. G., \& Crimins, J. L. (2018). Acetylcholine receptor stimulation for cognitive enhancement: Better the devil you know. Journal of Neuron, 98(6), 1064-6. [DOI:10.1016/j.neuron.2018.06.018] [PMID]

Blomquist, K. B., \& Danner, F. (1987). Effects of physical conditioning on information-processing efficiency. Perceptual and Motor Skills, 65, 175-86. [DOI:10.2466/pms.1987.65.1.175] [PMID]

Carro, E., Trejo, J. L., Busiguina, S., \& Torres- Aleman, I. (2001). Circulating insulin-like growth factor 1 mediates the protective effects of physical exercise against brain insults of different etiology and 
anatomy. The Journal of Neuroscice, 21(15), 5678-84. [DOI:10.1523/ JNEUROSCI.21-15-05678.2001] [PMCID]

Colberg, S. R., Sigal, R. J., Yardley, J. E., Riddell, M. C., Dunstan, D. W., \& Dempsey, P. C., et al. (2016). Physical activity/exercise and diabetes: A position statement of the American Diabetes Association. Diabetes Care, 39, 2065-79. [DOI:10.2337/dc16-1728] [PMID] [PMCID]

Colcombe, S. J., Kramer, A. F., Erickson, K. I., Scalf, P., McAuley, E., \& Cohen, N. J., et al. (2004). Cardiovascular fitness, cortical plasticity, aging. Proceedings of the National Academy of Sciences of the United States of America, 101, 3316-21. [DOI:10.1073/ pnas.0400266101] [PMID] [PMCID]

Cotman, C. W., \& Berchtold, N. C. (2006). Exercise a behavioral intervention to enhance brain health and brain plasticity. Trends in Neuroscience, 25(6), 295-301. [DOI:10.1016/S0166-2236(02)021434]

Danaei, G., Finucane, M. M., Lu, Y., Singh, G. M., Cowan, M. J., \& Paciorek C. J., et al. (2011). National, regional, and global trends in fasting plasma glucose and diabetes prevalence since 1980: Systematic analysis of health examination surveys and epidemiological studies with 370 country-years and 2.7 million participants. Lancet, 378(9785), 31-40. [DOI:10.1016/S0140-6736(11)60679-X]

Ding, Y. H., Young, C. N., Luan, X., Li, J., Rafols, J. A., \& Clark, J. C., et al. (2005). Exercise preconditioning ameliorates inflammatory injury in ischemic rats during reperfusion. Acta Neuropathologica, 109(3), 237-246. [DOI:10.1007/s00401-004-0943-y] [PMID]

Evans, D. A., Beckett, L. A., Albert, M. S., Hebert, L. E., Scherr, P. A., \& Funkenstein, H. H., et al. (1993). Level of education and change in cognitive function in a community population of older persons. Annals of Epidemiology, 3(1), 71-7. [DOI:10.1016/10472797(93)90012-S]

Flores-Gómez, A. A., de Jesús Gomez-Villalobos, M., \& Flores, G. (2019). Consequences of diabetes mellitus on neuronal connectivity in limbic regions. Synapse, 73(3), e22082.[DOI:10.1002/ syn.22082] [PMID]

Firouzjaei, M. A., Jafari, M. R., Eskandari, M., Anarkoli, I. J., \& Alipour, M. (2014). Aminoguanidine changes hippocampal expression of apoptosis-related genes, improves passive avoidance learning and memory in streptozotocin-induced diabetic rats. Cellular and Molecular Neurobiology, 34(3), 343-50. https://link. springer.com/article/10.1007\%2Fs10571-013-0018-5

Gao, L., Tang, Q., He, X., \& Bi, M. (2012). Effect of icariin on learning and memory abilities and activity of cholinergic system of senescence-accelerated mice SAMP10. Zhongguo Zhong yao za zhi = Zhongguo zhongyao zazhi, 37(14), 2117-21. [PMID]

Gordon, B., Benson, A., Bird, S., \& Fraser, S. (2009). Resistance training improves metabolic health in type 2 diabetes: A systematic review. Diabetes Research and Clinical Practice, 83(2), 157-75. [DOI:10.1016/j.diabres.2008.11.024] [PMID]

Grace, M. H., Esposito, D., Timmers, M. A., Xiong, J., Yousef, G., \& Komarnytsky, S., et al. (2016). Chemical composition, antioxidant and anti-inflammatory properties of pistachio hull extracts. Food Chemistry, 210, 85-95. [DOI:10.1016/j.foodchem.2016.04.088] [PMID]

Grealy, M. A., Johnson, D. A., \& Rushton, S. K. (1999). Improving cognitive function after brain injury: The use of exercise and virtual reality. Archives of Physical Medicine and Rehabilitation, 80(6), 661-7. [DOI:10.1016/S0003-9993(99)90169-7]
Guo, M., Lin, V., Davis, W., Huang, T., Carranza, A., \& Sprague S., et al. (2008). Preischemic induction of TNF-alpha by physical exercise reduces blood-brain barrier dysfunction in stroke. Journal of Cerebral Blood Flow and Metabolism, 28(8), 1422-30. [DOI:10.1038/jcbfm.2008.29] [PMID]

Harrison, F. E., Hosseini, A. H., Dawes, S. M., Weaver, S., \& May, J. M. (2009). Ascorbic acid attenuates scopolamine-induced spatial learning deficits in the water maze. Behavioural Brain Research, 28, 550-8. [DOI:10.1016/j.bbr.2009.08.017] [PMID] [PMCID]

Hasanein, P., \& Shahidi, S. (2012). Preventive effect of Teucrium Polium on learning and memory deficits in diabetic rats. Medical Science Monitor, 18(1), 41-6. [DOI:10.12659/MSM.882201] [PMID] [PMCID]

Henriksen, E. J. (2002). Invited review: Effects of acute exercise and exercise training on insulin resistance. Journal of Applied Physiology, 93(2), 788-96. [DOI:10.1152/japplphysiol.01219.2001] [PMID]

Jabbarpour, Z., Shahidi, S., Saidijam, M., Sarihi, A., Hassanzadeh T., \& Esmaili, R. (2014). Effect of tempol on the passive avoidance and novel object recognition task in diabetic rats. Brain Research, 101, 51-6. [DOI:10.1016/j.brainresbull.2013.12.013] [PMID]

Johansson, B. B., \& Ohlsson, A. L. (1996). Environment, social interaction, and physical activity as determinants of functional outcome after cerebral infarction in the rat. Experimental Neurology, 139(2), 322-7. [DOI:10.1006/exnr.1996.0106] [PMID]

Khalaj, A., \& Ahmadi, R. (2016). [The effect of treadmill exercise on catalepsy from reserpine-induced Parkinson model in diabetic male rat (Persian)]. KAUMS Journal (FEYZ), 20(5), 397-404. http:/ / feyz.kaums.ac.ir/article-1-3169-fa.html

Kucukatay, V., Agar, A., Gumuslu, S., \& Yargicoglu, P. (2007). Effect of sulfur dioxide on active and passive avoidance in experimental diabetes mellitus: relation to oxidant stress and antioxidant enzymes. The International Journal of Neurosciemce, 117(8), 1091-7. [DOI:10.1080/00207450600934531] [PMID]

Liu, J., Yeo, H. C., Overvik-Douki, E. O., Hagen. T., Doniger, S. J., \& Chu, D. W., et al. (2000). Chronically and acutely exercised rats: Biomarkers of oxidative stress and endogenous antioxidants. Applied Physiology, 89(1), 21-8. [DOI:10.1152/jappl.2000.89.1.21] [PMID]

Małczyńska, P., Piotrowicz, Z., Drabarek, D., Langfort, J., Małgorzata Chalimoniuk, M. (2019). The role of the Brain-Derived Neurotrophic Factor (BDNF) in neurodegenerative processes and in the neuroregeneration mechanisms induced by increased physical activity. Postepy Biochemii, 65(1), 2-8. [Doi: 10.18388/pb.2019_251] [PMID]

Mattson, M. P., Culmsee, C., Yu, Z., \& Camandola, S. (2000). Roles of nuclear factor kappa $\mathrm{B}$ in neuronal survival and plasticity. Journal of Neurochemistry, 74(2), 443-56. [DOI:10.1046/j.14714159.2000.740443.x] [PMID]

Monti, B., Polazzi, E., \& Ontastabile, A. (2009). Biochemical, molecular and epigenetics mechanisms of valproic acid neuroprotection. Current Molecular Pharmacology, 2(1), 95-109. [DOI:10.2174/1 874467210902010095] [PMID]

Mozdastan, Sh., Ebrahimzadeh, M. A., \& Khalili, M. (2015). Comparing the Impact of Different Extraction Methods on Antioxidant Activities of Myrtle (Myrtus communis L.). Journal of Mazandaran University and Medical Sciences, 25(127), 10-24. http://jmums.mazums.ac.ir/files/site1/user_files_0d0bf0/ nouri70-A-10-5029-91-ff772df.pdf 
Nishimura, S., Taki, M., \& Takaishi, S. (2000). Structures of 4-aryl-coumarin (Neoflavone) dimmers isolated from pistaciachinsis BUNGE and their estrogen - like activity. Chemical $\mathcal{E}$ Pharmaceutical Bulletin, 48(4), 505-8. [DOI:10.1248/cpb.48.505] [PMID]

Ogonovszky, H., Sasvari, M., Dosek, A., Berkes, I., Kaneko, T., Tahara, S., \& et al. (2005). The Effect of Modrate, Strenuous, and Overtraining on Oxidative Stress Markers' and DNA Repair in RAT Liver. Canadian Journal of Applied Physiology, 30(2), 186-95. [DOI:10.1139/h05-114] [PMID]

Ogonovszky, H., Berkes, I., Kumagai, S., Kaneko, T., Tahara, S., \& Goto, S., et al. (2005). The effects of moderate, strenuous- and over-training on oxidative stress markers, DNA repair, and memory, in rat brain. Neurochemistry International, 46(8), 635-40. [DOI:10.1016/j.neuint.2005.02.009] [PMID]

Ohlsson, A. L., \& Johansson, B. B. (1995). Environment influences functional outcome of cerebral infarction in rats. Stroke, 26(4), 644-9. [DOI:10.1161/01.STR.26.4.644] [PMID]

Patil, C. S., Singh, V. P., \& Kulkarni, S. K. (2006). Modulatory effect of sildenafil in diabetes and electroconvulsive shockinduced cognitive dysfunction in rats. Pharmacological Reports, 58(3), 373-80. http://citeseerx.ist.psu.edu/viewdoc/downloa d?doi=101.1.377.9465\&rep=rep1\&type $=$ pdf

Radak, Z., Toldy, A., Szabo, Z., Siamilis, S., Nyakas, C., \& Silye, G., et al. (2006). The effects of training and detraining on memory, neurotrophins and oxidative stress markers in rat brain Neurochemistry International, 49(4), 387-92. [DOI:10.1016/j. neuint.2006.02.004] [PMID]

Ramanathan, M., Jaiswal, A. K., \& Bhattacharya, S. K. (1998). Differential effects of diazepam on anxiety in streptozotocin induced diabetic and non - diabetic rats. Psychopharmacology (Berl), 135, 361-7. [DOI:10.1007/s002130050523] [PMID]

Savelev, S. U., Okello, E. J., \& Perry, E. K. (2004). Butyryl and acetyl-cholinesterase inhibitory activities in essential oils of Salvia species and their constituents. Phytotherapy Research, 18, 315-24. [DOI:10.1002/ptr.1451] [PMID]

Sevcan, E., Ozlem, G. U., Reinhold, C., \& Ralf, M. S. (2017). Determination of pistachio (Pistacia vera L.) hull (exo - and mesocarp) phenolics by HPLC-DAD-ESI/MS and UHPLCDAD-ELSD after ultrasound-assisted extraction. Journal of Food Composition and Analysis, 62, 103-14. [DOI:10.1016/j. jfca.2017.04.013]

Shahbazi, P., \& Maleknia, N. (2008). Harper biochemistry for college students, Tehran: Tehran University Press.

Spencer, J. P. (2008). Food for thought: The role of dietary flavonoids in enhancing human memory, learning and neurocognitive performance. The Proceeding of the Nutrition Society. 67, 238-52. [DOI:10.1017/S0029665108007088] [PMID]

Spiegelman, B. M. (2013). Regulation of adipogenesis: Toward new therapeutics for metabolic disease. Diabetes, 62(6), 1774-82. [DOI:10.2337/db12-1665] [PMID] [PMCID]

Thirugnanasambantham, P., Viswanathan, S., Mythirayee, C., Krishnamurty, V., Ramachandran, S., \& Kameswaran, L. (1990). Analgesic activity of certain flavone derivatives: a structure-activity study. Journal of Ethnopharmacology, 28, 207-14. [DOI:10.1016/0378-8741(90)90030-W]

Van, P. H., Kempermann, G., \& Gage, F. H. (1999). Running increases cell proliferation and neurogenesis in the adult mouse dentate gyrus. Nature Neuroscience, 2(3), 266-70. [DOI:10.1038/6368] [PMID]

Verma, S., \& Bordia, A. (1998). Antioxidant property of Saffron in man. Indian Journal of Medical Science, 52(5), 205-207.

Viggiano, A., Viggiano, A., Monda, M., Turco, I., Incarnato, L., \& Vinno, V., et al. (2006). Annurca apple-rich diet restores longterm potentiation and induces behavioral modifications in aged rats. Expimental Neurology, 199, 354-61. [DOI:10.1016/j. expneurol.2006.01.001] [PMID]

Wang, Y., Wang, L., Wu, J., \& Cai, J. (2006). The in vivo synaptic plasticity mechanism of Egb761-induced enhancemen of spatial learning and memory in aged rats. British Journal of Pharmacology, 148, 147-53. [DOI:10.1038/sj.bjp.0706720] [PMID] [PMCID]

Yi, S. S. (2015). Effects of exercise on brain functions in diabetic animal Models. World Journal of Diabetes, 6(4), 583-97. [DOI:10.4239/wjd.v6.i4.583] [PMID] [PMCID]

Young, I. S., Torney, J. J., \& Trimble, E. R. (1992). The effect of ascorbate supplementation on oxidative stress in the streptozotocin diabetic rat. Free Radical Biology and Medicine, 13(1) 41-6. [DOI:10.1016/0891-5849(92)90164-C]

Yuede, C. M., Zimmerman, S. D., Dong, H., Kling, M. J., Bero, A W., \& Holtzman, D. M., et al. (2009). Effects of voluntary and forced exercise on plaque deposition, hippocampal volume and behavior in the Tg2576 mouse model of Alzheimer's disease. Neurobiology of Disease, 35(3), 426-32. [DOI:10.1016/j. nbd.2009.06.002] [PMID] [PMCID]

Zhang, P. H., Tang, H. Q., Zheng, M. Z., Chen, Y. Y., \& Shen, Y. L. (2011). Effect of total flavonoids from Chrysanthemun morifolium on learning and memory in aging mice. Zhongguo Ying Yong Sheng Li Xue Za Zhi, Aug; 27(3), 368-71. https:// www.researchgate.net/publication/51812144 
This Page Intentionally Left Blank 